\title{
Las infografías como herramienta didáctica: aplicación en la enseñanza universitaria
}

Elena Fernández de Molina Ortés

Universidad de Granada

efortes@ugr.es

\section{\$EWWFW}

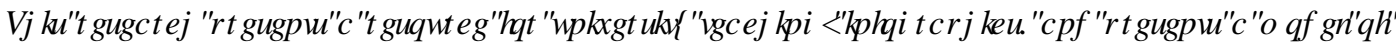

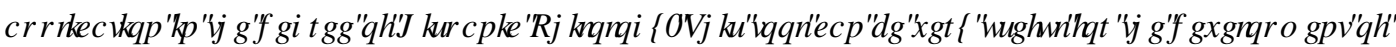

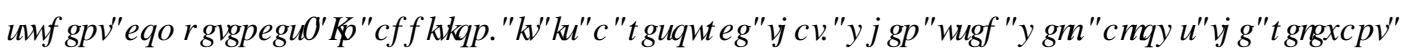

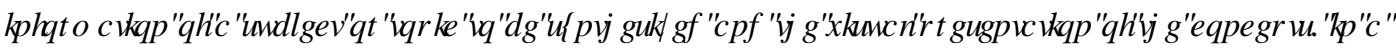

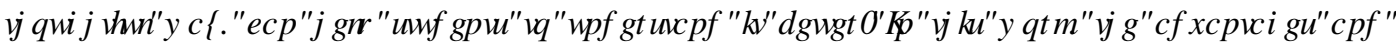

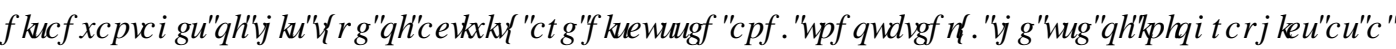
UDFKIQJ $\square$ P HKRGLLUUXSSRUWHGD

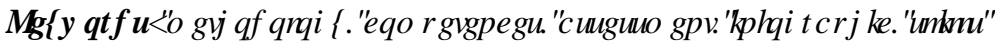

\section{HXP HQ}

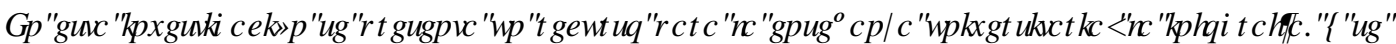

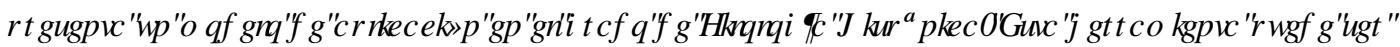

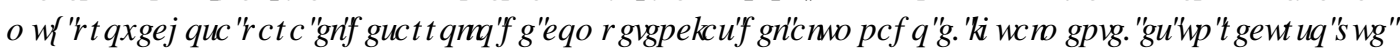

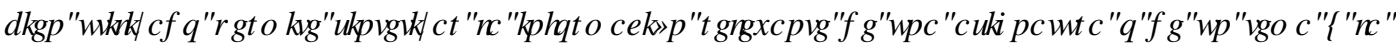

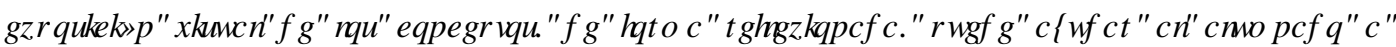

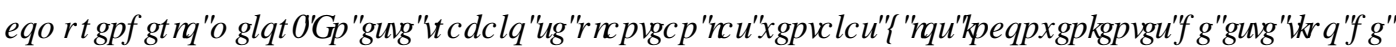

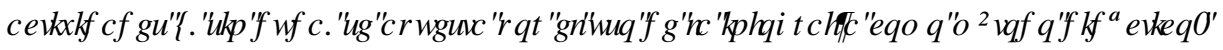

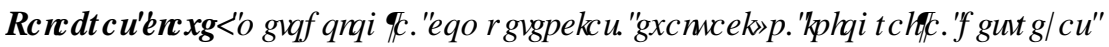

\section{Introducción}

Las comunicaciones tendrán una extensión mínima de 5 folios y máxima de 15 ; y deberán cosntar de los siguientes apartados:

- Introducción

- Objetivos

- Desarrollo de la innovación

- Resultados

- Conclusiones

- Referencias 


\section{Presentación}

Durante la etapa universitaria, el alumnado debe adquirir competencias y destrezas que lo preparen para su futuro y, sobre todo, para el desarrollo de la carrera universitaria y el ámbito laboral. Sin embargo, es cierto que a veces el profesorado, cuando lo hace, propone prácticas que permiten comprobar los conocimientos que ha logrado asimilar el discente, pero no evalúa cómo lo ha hecho.

Con el cambio académico que desde el año 2010 comenzó a implantarse en el sistema universitario español, la metodología universitaria cambió totalmente, tanto desde el punto de vista del profesorado universitario como del alumnado, algo evidente, pues "la renovación metodológica es consustancial al espíritu universitario y, por lo tanto, sería un error identificarla con la oportunidad de cambio que se produce con la construcción del Espacio Europeo de Educación Superior (Pétriz, 2007)”. Desde este nuevo punto de vista, la enseñanza pasó de ser unidireccional a ser multidireccional, y la clase magistral se amplió con actividades y prácticas que permiten al alumnado ser más consciente de su aprendizaje y de asimilar los conocimientos adquiridos en el aula. Además, el alumnado, tras finalizar su formación, es capaz de enfrentarse de una forma mucho más autónoma al mundo laboral (Alonzo et al., 2012; Carbache, 2015; López \& Solarte, 2013; Palacios et al., 2014).

Actualmente, son muchas las herramientas que nos permiten ayudar a nuestros estudiantes a asimilar y a comprender lo que se trabaja en el aula y de forma individual. Como docentes, debemos poner a su disposición recursos que, además, no solo usen para una asignatura, sino que puedan trasponer estas nuevas herramientas a otras áreas y, también, a su ámbito laboral.

\subsection{La asignatura de Fonética y Fonología del español}

Esta propuesta didáctica se enmarca en la asignatura de Fonética y Fonología del español que se imparte, en la Universidad de Granada, en el primer año del grado de Filología Hispánica. Es una materia compleja, dado que el alumnado debe adquirir conceptos no solo relacionados con la transcripción fonética o la identificación de sonidos, sino que también debe conocer el objeto de estudio y las distintas ramas de la Fonética (fonética articulatoria, fonética acústica y fonética perceptiva), así como los procesos fonológicos que describen el sistema vocálico y consonántico en español.

En un primer momento, y aunque si bien es cierto que es una asignatura que es bastante interesante para el alumnado porque, entre otras cosas, no han realizado nunca estudios de este tipo en etapas anteriores, el temario es complejo y abstracto, sobre todo en los primeros temas. Concretamente, ya se ha mencionado anteriormente, en el estudio de las ramas de la fonética el alumnado tiene que explicar, desde un punto de vista biológico y acústico cómo se produce la comunicación; es decir, tiene que explicar un proceso que, aunque conoce (porque sí lo ha trabajado en Educación Primaria y Educación Secundaria), no lo ha aplicado a esta rama y, en muchas ocasiones, no lo ha estudiado recientemente, pues hay que tener en cuenta que el alumnado de Filología Hispánica no siempre ha realizado el bachillerato de Ciencias. En este tema se presenta, por tanto, una serie de conocimientos conocidos, que posteriormente tendrán que relacionar con nuevos conceptos: posición de los articuladores activos y pasivos en la pronunciación de los sonidos; características de las ondas acústicas y su representación en oscilogramas y espectrogramas; análisis de los decibelios y frecuencias de un sonido y su recepción por parte del oyente; percepción de los sonidos.

Posteriormente, en los temas siguientes siempre se tendrán presentes todos los conceptos trabajados, por lo que es fundamental que el alumnado los comprenda y los pueda aplicar, sin problemas, durante el curso.

\section{2. ¿Qué es una infografía}

Una infografía es un documento con el que, a partir de la combinación de imágenes y texto, se ofrece una información esquemática y atractiva de un contenido más o menos complejo. Normalmente son los 
docentes los que elaboran infografías para el alumnado como base para las explicaciones que realizan en clase o, simplemente, para que tengan un esquema para estudiar. Sin embargo, teniendo en cuenta las metodologías activas de aprendizaje, este tipo de recursos puede ser relevante para que sea el propio discente el que organice y presente la información de una forma visual realizando, así, una labor de síntesis y de comprensión del tema que se le propone (Valero, 2008). De hecho, es un tipo de metodología de aprendizaje relativamente reciente pero que puede tener muchas posibilidades didácticas (Minervini, 2006; Simón, 2020).

\section{Objetivos}

El objetivo de principal de este trabajo es presentar el diseño de un modelo didáctico mediante el uso de infografías en el ámbito universitario.

Asimismo, en el desarrollo de este proyecto se tendrán en cuenta, también, otros objetivos específicos:

- Describir el método de trabajo mediante infografías propuesto al alumnado.

- Realizar una revisión de las plataformas con las que se pueden realizar estas presentaciones en la actualidad.

- Identificar las ventajas, beneficios y también inconvenientes del uso de esta herramienta en la enseñanza universitaria.

Por último, es necesario tener en cuenta que en este proyecto se incluye, también, un apartado relativo a la evaluación del alumnado. Aunque si bien es cierto que la docente evaluó las infografías presentadas por los grupos de trabajo, se propuso un método alternativo como método de evaluación que favoreciera la autoevaluación y la valoración grupal: el foro de clase. Este tipo de evaluaciones suelen ser beneficiosas para el alumnado, por lo que en esta investigación se detallarán, también, los beneficios de la valoración grupal.

\section{Desarrollo de la innovación}

La propuesta didáctica, como se ha indicado anteriormente, se realiza para trabajar el tema 2 de la asignatura de Fonética y Fonología del español. En este caso, se plantea al alumnado realizar una infografía en grupos a partir de la cual deberán reproducir el proceso de comunicación desde un punto de vista fonético. Para ello utilizará una combinación de imágenes y texto que le permita, con pocas palabras, describir el sistema comunicativo. En el ámbito académico (bachillerato o en el propio primer curso de grado), el alumnado ya ha realizado presentaciones escritas y orales, usando herramientas como Power Point o incluso Prezi, que cada vez es más empleado por el alumnado universitario. Realizar una presentación de información de este tipo es mucho más complicado, porque no disponen de texto.

\subsection{Objetivos didácticos y competencias}

\section{पापा2 ENAMRRVGG FUFRV}

Con esta actividad se persiguen una serie de objetivos que permitirán al alumnado comprender los conceptos trabajados en el tema sobre las ramas de la Fonética de la asignatura. Concretamente, con la elaboración de la infografía:

- El estudiante podrá sintetizar la información relevante sobre los distintos momentos del sistema comunicativo desde un punto de vista fonético.

- Realizará un trabajo de recopilación de todos los materiales utilizados en el tema y podrá explicarlos de una forma visual, lo cual favorecerá, también, el desarrollo de nuevas formas de estudio. 
- Realizará un trabajo en grupo, lo que favorecerá también el trabajo en equipo y la relación con otros compañeros de clase, utilizando roles de trabajo que, sin duda, serán fundamentales durante toda su etapa académica y su vida laboral.

\section{૧प⿴囗7WEDWFRQFRP SHMQFWW}

Si tenemos en cuenta el uso de la infografía en la asignatura del grado de Filología Hispánica y se toman en consideración algunas de las competencias que todo graduado debe alcanzar al terminar su etapa universitaria, con el empleo de estas herramientas el estudiante desarrolla gran parte de GWFRP SHARFIDV IQWUXP HQWXON de su etapa formativa:

- Analizar y sintetizar toda la información adquirida.

- Tener capacidad de organización y planificación

- Gestionar la información, es decir, es capaz de localizar, manejar y sintetizar información bibliográfica e información contenida en bases de datos y otros instrumentos informáticos y de Internet.

- Ser capaz de resolver problemas.

- Ser capaz de tomar de decisiones.

- Aplicar los conocimientos en la práctica, especialmente en la enseñanza, la investigación y la divulgación de las futuras inserciones laborales.

Asimismo, y dado que es un trabajo que se realiza de forma grupal y que, además, y tal y como se comprobará posteriormente, se hace una evaluación crítica del trabajo de otros compañeros, con esta actividad se trabajan otras FRP SHAQFIDV, en este caso de tipo SHURQDO

- Trabajar en equipo.

- Tener habilidades en las relaciones interpersonales.

- Reconocer la diversidad y la multiculturalidad.

- Adquirir un razonamiento crítico.

- Adquirir un compromiso ético.

- Tener capacidad crítica y autocrítica.

Finalmente, y en cuanto a las FRP SHMPFLVUMMPP IFDV, el alumnado trabaja con otras habilidades como:

- Trabajar y aprender de forma autónoma.

- Revisar con rigor y controlar, evaluar y garantizar la calidad.

- Saber exponer y defender con claridad los objetivos y resultados del trabajo.

- Transferir los resultados de su trabajo e investigación a la sociedad.

- Generar nuevas ideas (creatividad).

\subsection{El trabajo con infografías}

Para hacer el trabajo, se presenta al alumnado un índice en el que se indica la estructura informativa que debe tener la infografía y posibles herramientas para realizarla. Vamos a desarrollar brevemente cada uno de los apartados ${ }^{1}$.

${ }^{1}$ Se puede comprobar el modelo de trabajo en el Anexo 1. 


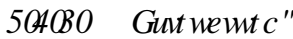

La infografía debe constar, para ser evaluada positivamente, al menos 4 apartados en los que se presentarán los datos sobre cómo se produce el sistema de comunicación desde un punto de vista fonético. Concretamente, el alumnado tendrá que la información de lo más general a lo más específico siguiendo el siguiente esquema:

a. Presentación. En esta sección se realiza un $U H X P$ HQURLDP HQWHIXWDOde cómo se produce el sonido desde un punto de vista fonético. Se presentarán, realizando una combinación de imágenes y textos, las ramas de la fonética según los elementos que intervienen en cada apartado.

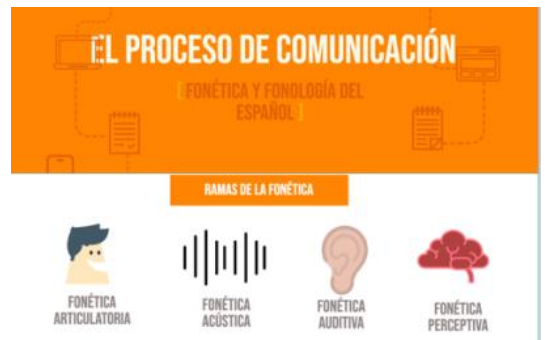

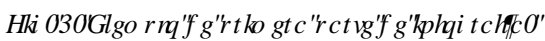

b. Fonética articulatoria. Este apartado debe contener las 3 cavidades principales que permiten la fonación y una representación de las partes más importantes de cada una de ellas.

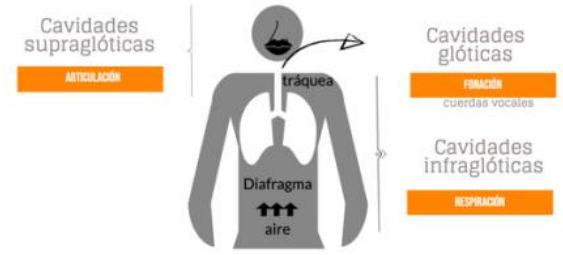

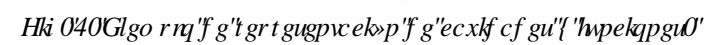

c. Fonética acústica. En esta sección se propondrán las características del sonido desde un punto de vista físico, se presentarán tipos de ondas y variación acústica de las mismas

d. Fonética auditiva y perceptiva. El último estadio de la comunicación, la llegada del sonido al receptor, se produce desde un punto de vista auditivo y, posteriormente, perceptivo. En este apartado el alumnado tendrá que describir este último paso.
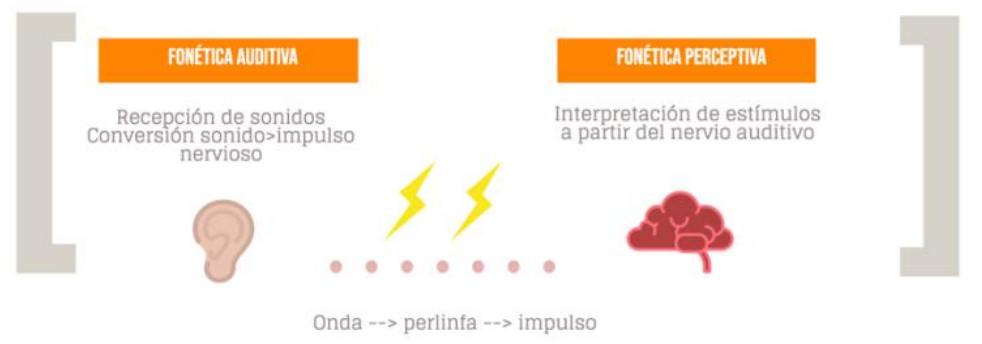

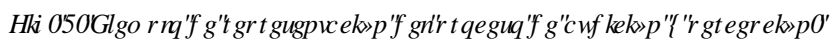

\section{पषण + HUP IHQW}

Durante la sesión previa a la preparación de la actividad se proporciona al discente herramientas con las que elaborar infografías de una forma sencilla. Una de ellas ya la conocen (Power Point), aunque no han trabajado con este programa para crear infografías. Para aquellos que quieran usarlo, se les explica que pueden ampliar el tamaño de la diapositiva y configurarla como si fuera un póster, lo cual les permite 
organizar la información, también, de forma infográfica. Es muy importante señalar que en ningún momento se obliga al alumnado a utilizar una herramienta, sino que se le ofrecen distintas posibilidades.

Sin embargo, es más representativo para el grupo utilizar herramientas novedosas que le permiten crear infografías distintas, ya que cuentan con más funcionalidades. Nos referimos, por ejemplo, a 2 páginas web que permiten crear no solo infografías, sino también otro tipo de formatos gracias a sus plantillas predefinidas, concretamente https://www.canva.com/es_es/ (Fig. 4) y www.piktochart.com (Fig. 5).

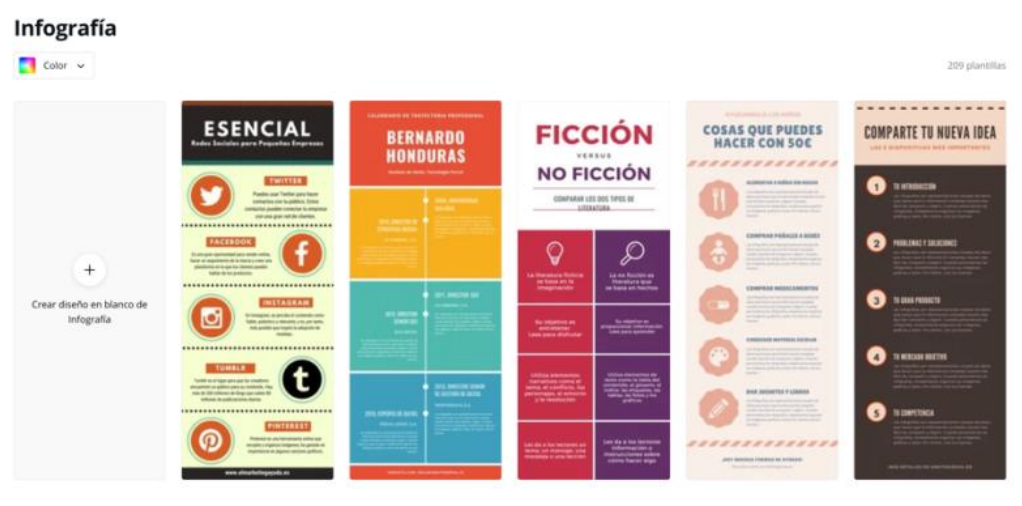

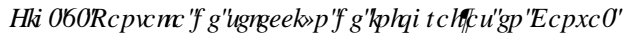

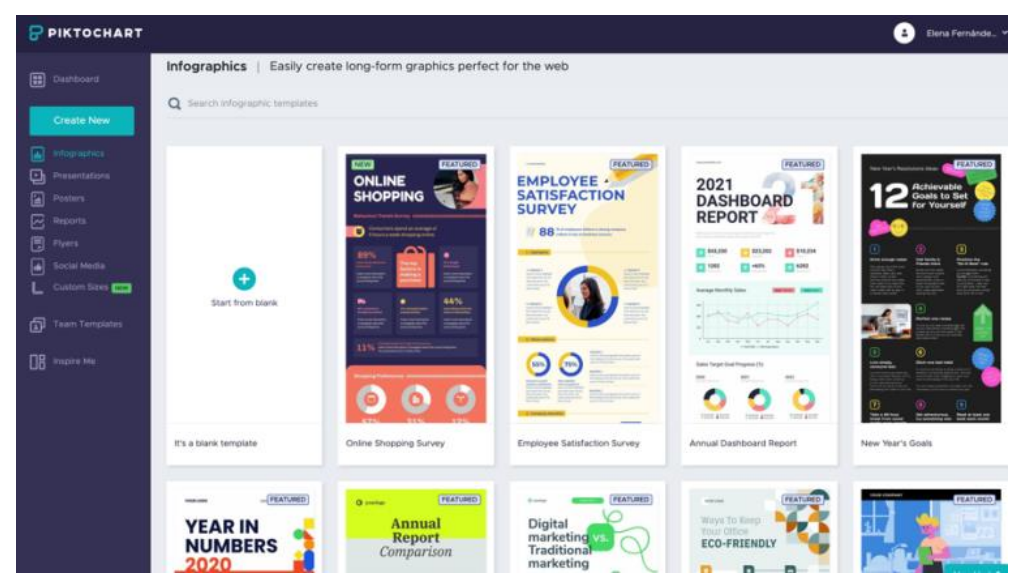

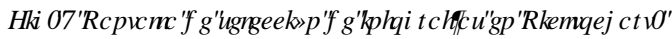

Lo interesante de estas herramientas es que, además de facilitar el desarrollo creativo del alumnado y su capacidad de síntesis, les permite usar múltiples herramientas visuales para desarrollar todo lo que se ha visto en clase. Las dos páginas contienen iconos relacionados con múltiples temas, incluidos temas biológicos y acústicos, tan importantes para el desarrollo del trabajo que se plantea en este curso.

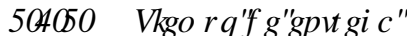

El alumnado tendrá que entregar la tarea mediante la plataforma docente de la Universidad de Granada 1 semana después de haber comenzado a trabajar en clase. De hecho, el primer día de trabajo se realiza en el aula, momento en el que el profesorado puede contestar las dudas del grupo.

\subsection{Una herramienta diferente de evaluación: el foro}

Esta actividad, la creación de la infografía, es distinta, y su evaluación también se realiza utilizando un método de evaluación diferente: HOIRLR GHFDMH En realidad, hay que tener en cuenta que se trata de un trabajo en grupo muy visual pero sobre un mismo tema, por lo que hacer una presentación en la clase puede 
llevar a un agotamiento en el curso. Sin embargo, una manera de conseguir que todo el grupo vea las infografías de sus compañeros y compañeras es subir su imagen y realizar comentarios sobre el trabajo. En un primer momento se planteó este tipo de evaluación al alumnado y fue muy bien acogida.

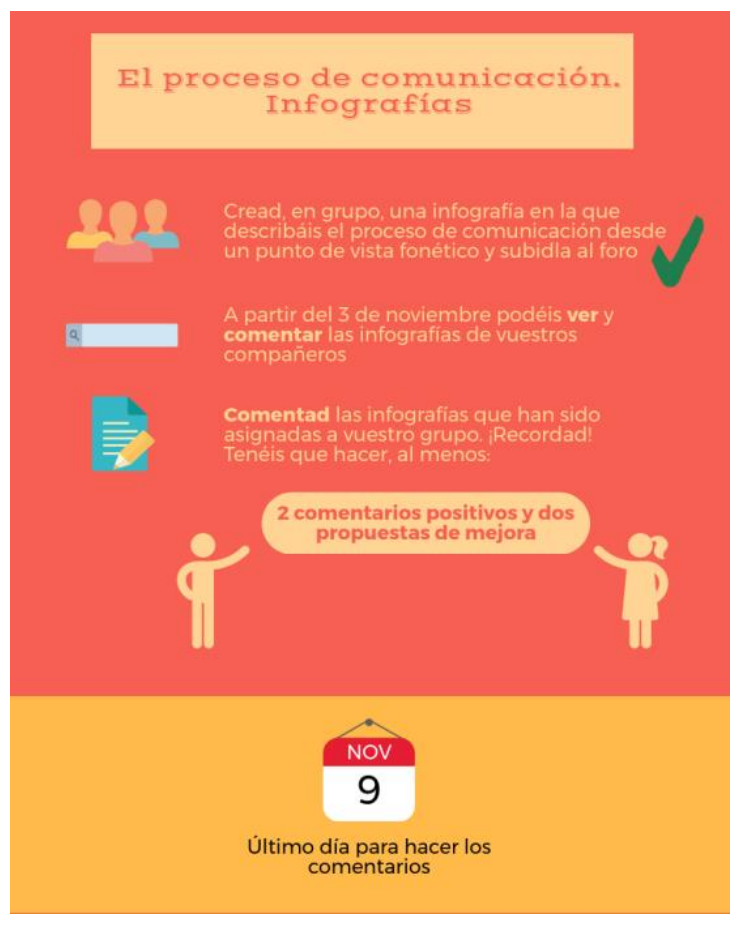

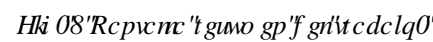

No obstante, y para evitar que la evaluación no fuera sincera (es muy complicado, sobre todo en los primeros cursos, realizar comentarios no siempre positivos de los compañeros), se propuso al alumnado que aquellas infografías que tenían que valorar tuvieran, al menos, 2 comentarios positivos pero, también, 2 comentarios con propuestas de mejora sobre aspectos como el color, la distribución de la información, el contenido, etc. Con esto se desarrollaba la capacidad crítica del alumnado no solo al dirigir comentarios (positivos y negativos) a sus compañeros/as, sino también al asumir las opiniones de los demás.

\section{Resultados y evaluación de la actividad}

Tras realizar el trabajo en grupo, se pudo comprobar que la actividad tuvo una gran acogida por parte del alumnado: todos los grupos realizaron un trabajo impecable, y todos y cada uno de ellos participaron de forma activa y participativa en los foros de evaluación, aportando muchas ideas y propuestas de mejora a sus compañeros.

De hecho, en las notas globales de los grupos de trabajo se puede comprobar que la actividad fue muy positiva en las calificaciones: la nota media de la parte primera de la actividad (elaboración de la infografía) fue de un 7,8, una calificación alta teniendo en cuenta que no solo se evaluaba el contenido (que es fundamental) sino cómo lo representaban para después poder estudiar los conceptos con más claridad.

Por otro lado, se propuso al alumnado un cuestionario individual en el que ellos mismos pudieran valorar la actividad. Con esta evaluación, la docente podía conocer cuál era la verdadera opinión de la clase (el cuestionario era anónimo y voluntario), y tener un IHHEDFNde la actividad. El cuestionario fue respondido por 35 estudiantes del curso (lo que supone un 50\% del total del alumnado). 
Concretamente, el test fue contestado por 35 estudiantes (50\% del curso). Por una parte, se plantearon una serie de preguntas sobre el uso de las infografías para representar visualmente el tema que habían visto en clase.

P1. ¿Crees que esta actividad se corresponde con los contenidos trabajados en clase?

P2. ¿Crees que es relevante para la comprensión del tema?

P3. ¿Te ha resultado interesante el uso de nuevas herramientas para realizar este tipo de presentaciones?

P4. ¿Te ha resultado interesante el uso de infografías como herramienta de evaluación?

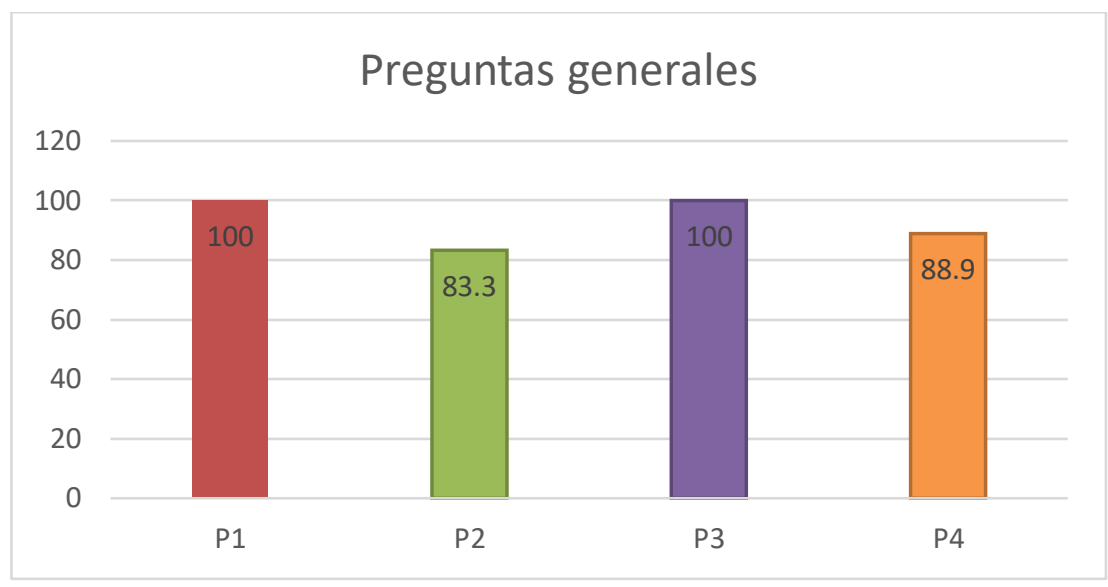

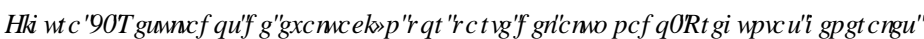

Como se puede observar en la Figura 7, el alumnado reconoce que, efectivamente, esta actividad se relaciona con los contenidos trabajados en clase (100\%) y que es útil conocer este tipo de herramientas para realizar presentaciones (100\%). Si bien es cierto que tuvo una gran acogida, es cierto que solo un $83,3 \%$ del grupo afirmó que el uso de infografías permite comprender o afianzar los conocimientos del tema y, aproximadamente, el mismo porcentaje de los alumnos $(88,9 \%)$ consideraron conveniente este trabajo como método de evaluación. Es cierto que algunos discentes comentaron que era un trabajo que necesitaba de mucho tiempo de preparación y que, aunque era entretenido y útil, realmente era costoso (la mayoría tardaron entre 3 y 5 horas en elaborarlo). No obstante, los datos generales de la actividad son, sin duda, relevantes, y revelan un interés del estudiantado hacia la actividad.

Por otra lado, y en cuanto a la evaluación que los propios alumnos hicieron del trabajo de sus compañeros, los resultados no fueron tan positivos como la elaboración de la actividad. Para conocer su opinión sobre este método, se plantearon 2 nuevas preguntas en el cuestionario:

- P5. Con los comentarios en los foros, ¿crees que has desarrollado nuevas destrezas y competencias?

- P6. ¿La lectura de las propuestas hechas por tus compañeros han sido relevantes para tu desarrollo académico? 
En la Pregunta 5 se pretendía que el alumnado fuera consciente de la importancia de la autoevaluación y de la crítica (constructiva) hacia el trabajo de los compañeros, desarrollando de esta forma nuevas destrezas y competencias, fundamentales en su futuro. Esta pregunta fue evaluada con una escala de puntuación de 1 al 10, y en este caso, el promedio de calificación fue bastante elevado (7). Aunque si bien es cierto que varios grupos tuvieron problemas con los comentarios de sus compañeros, no fue una percepción general; la mayoría aportó consejos y recomendaciones interesantes que fueron aceptadas y agradecidas por el grupo. De hecho, el 72,2\% afirmó que la lectura de las propuestas que habían hecho sus compañeros habían sido relevantes para su desarrollo académico, por lo que en un principio podríamos confirmar que este método de evaluación puede ser aplicado a una actividad de una clase de primero de grado y que, sobre todo, tiene efectos positivos en un grupo de este curso.

Finalmente, y para concluir con esta revisión, los alumnos también puntuaron de forma general la actividad, y lo hicieron con un 8 .

\section{Conclusiones}

Las actividades en las que se incluyen nuevas formas de presentación de resultados y nuevos procedimientos de evaluación pueden tener efectos muy positivos en los alumnos de grado de las universidades españolas. Por una parte, la creación de nuevos métodos de estudio y adquisición de contenidos mediante plataformas digitales en las que se pueden elaborar materiales visuales y atractivos para el alumnado puede ser un punto de partida para ampliar los horizontes de la comprensión de conceptos teóricos y prácticos. Por otra parte, incluir al grupo de clase en el proceso de evaluación de sus compañeros puede ser también una forma de traspasar la pared de la calificación tradicional, y puede enseñar al alumnado a valorar desde un punto de vista profesional y grupal el trabajo de los demás.

Es cierto que, según nuestra experiencia, la creación de infografías tuvo una buena acogida por parte del alumnado, y que la mayor parte del grupo, tal y como se ha podido comprobar, disfrutó elaborándola con sus compañeros/as. Sin embargo, hay alumnos y alumnas que no se sintieron cómodos con actividades creativas, por lo que en muchas ocasiones tuvieron que delegar en otros compañeros del grupo la creación de la propia infografía. Aunque en cierta forma para el alumnado esto suponía un problema, en realidad era una solución desde el punto de vista grupal, aunque no siempre fue percibido de esa manera. De hecho, la buena organización del grupo hacía que el trabajo final fuera realmente positivo y bien evaluado.

Finalmente, y en cuanto a la evaluación mediante foros, supuso una interesante reflexión tanto del trabajo de los compañeros como de los propios trabajos de cada grupo. Es cierto que el alumnado aún está en el primer curso del grado, pero es muy importante saber valorar tanto positiva como negativamente otras actividades ya que, en realidad, cuando se hace, también se valora el propio trabajo. Quizás en estos primeros cursos del grado es un tipo de evaluación menos recomendable, dado que aún no han desarrollado totalmente su capacidad crítica, pero puede ser un punto de partida interesante para ellos mismos.

\section{Referencias}

Alonzo, D., Moguel, S., \& Arceo, L. (2012). "Transformación de la docencia hacia el enfoque

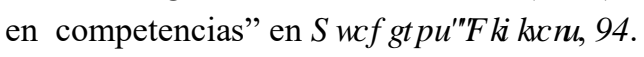

Carbache, C. (2015). "El aprendizaje en la educación superior" en

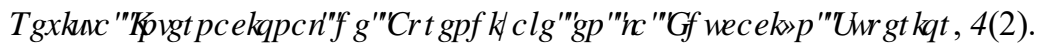

López, M., \& Solarte, J. (2013). "Evaluación por competencias: una alternativa para valorar el desempeño docente universitario" en 7HQCHQFWV, 0 (1), 216-257. 
Minervini, M.A. "Las infografías interactivas en la práctica educativa de la Biología” en $5 D] y Q$ Q ISDDEED, 49.

Palacios, P., Núñez, N., \& Arnao, M. (2014). “Formación universitaria basada en competencias en ) QP HQ प(1), 3-13.

Pétriz, F. (2007). "Estrategias para el cambio metodológico en la universidad española" en / D\&\&XMUYQ

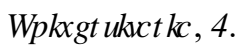

Simón Dolz, Y. (2020). "Metodología para el uso de las infografías didácticas en el proceso pedagógico de posgrado del centro de estudios de tecnologías y sistemas" en $\& R Q D Q R, 74$, pp. 12-21.

Valero, J. (2008). "La infografía digital en el ciberperiodismo" en 5HLLDV/ DUQDGH\&RP XQRFDFIyQ6RFIDO $63(11)$.

ANEXO 1

\section{PRÁCTICA 1. EL PROCESO DE COMUNICACIÓN}

Fonética y fonología del español

En esta práctica realizaréis, en grupo, un trabajo en el que tendréis que describir el proceso de comunicación desde un punto de vista fonético. El trabajo se basa en la elaboración de una infografía en la que, mediante la combinación de imágenes y texto, expliquéis este complejo proceso.

Tenéis que tener en cuenta que, en vuestro trabajo, las imágenes deben explicar el proceso propiamente dicho y el texto simplemente servirá para delimitar algunas partes del proceso o para hacer referencia a conceptos teóricos que sean necesarios en la propia explicación.

\section{ESTRUCTURA DEL TRABAJO}

La infografía debe tener, al menos, 4 apartados:

- Introducción: resumen descriptivo del proceso de comunicación

- La producción del sonido (proceso de fonación-fonética articulatoria)

- La transmisión de la información mediante ondas (fonética acústica)

- $\quad$ La recepción del sonido (fonética auditiva)

El trabajo, tal y como se ha anunciado en el primer párrafo de esta guía, debe ser colaborativo y debe ser elaborado entre todos los miembros del grupo. 


\section{2. ¿CÓMO CREAR UNA INFOGRAFÍA?}

Para crear una infografía tenéis 3 posibilidades:

- Power Point. Podéis crear una infografía con el propio PPT. Lo único que tenéis que hacer es cambiar la configuración de la plantilla. Pincháis en configuración e incluís los siguientes datos de configuración ${ }^{2}$ :

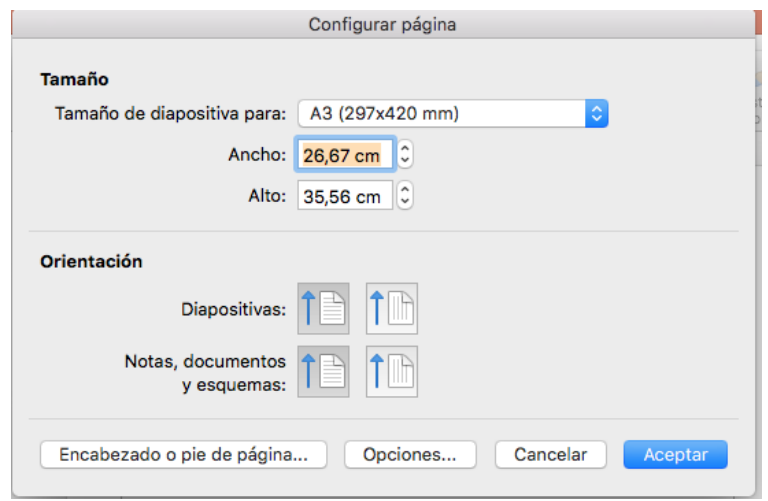

A partir de ahí podéis cambiar el diseño de la diapositiva como si fuera un simple Power Point y agregar elementos (formas, gráficos, imágenes etc.)

- Canva y Picktochart. En las siguientes páginas: https://create.piktochart.com/ y https:/www.canva.com/ tenéis dos herramientas para crear infografías. Podéis encontrar modelos ya predefinidos que os pueden servir para crear un trabajo más original.

- Cómo usar Canva:

https://www.dropbox.com/s/n7tdoznzfke419x/CANVA.mov?dl=0

○ Cómo usar Picktochart:

https://www.dropbox.com/s/k8alpli1jsp5fsf/PICKTOCHART.mov?dl=0

3. Fecha de entrega del trabajo: 3 de noviembre

4. Método de entrega: Los trabajos se subirán al foro creado en PRADO en el apartado de "Prácticas". Cada grupo abrirá un nuevo grupo de discusión. En el asunto escribirá el NOMBRE DEL GRUPO y en el mensaje puede incluir información sobre el trabajo.

${ }^{2}$ Para que la plantilla de Power Point se muestre como una infografía tenéis que seleccionar la orientación vertical.

(c)) BY-NC-ND 2021, Universitat Politècnica de València

CRQJHMR, Q5 HGHपिए। 


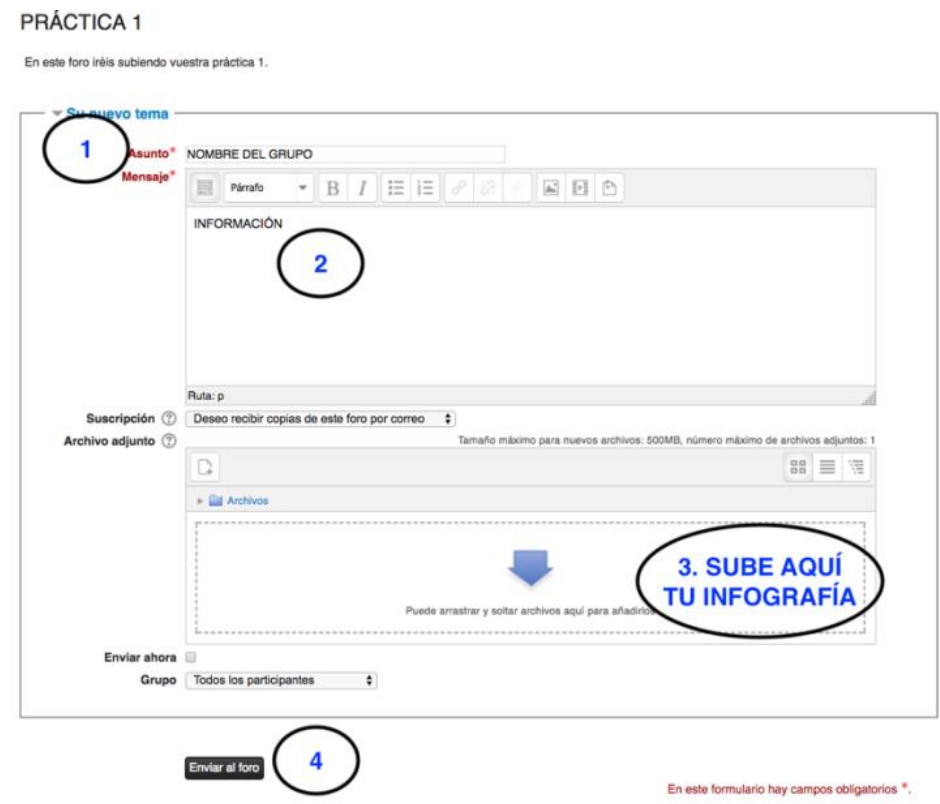

Por último, en la parte inferior, arrastra el archivo con tu infografía y envía al foro el mensaje.

Dado que las infografías de todos los grupos serán compartidas, los compañeros de otros grupos pueden hacer comentarios sobre los trabajos presentados. Es recomendable y se evaluará positivamente la interacción en los foros. Si realizáis un comentario, incluid el nombre del grupo en la despedida ${ }^{3}$.

\section{Evaluación}

La evaluación del trabajo se realizará atendiendo a los siguientes criterios:

- Presentación de los contenidos más relevantes del proceso de comunicación desde un punto de vista fonético $(60 \%)$

- Uso de términos técnicos (ejemplos: cavidades, tipos de ondas, partes de la percepción del sonido)

- Corrección lingüística y concreción de la información

- Correcto uso de las imágenes y el texto para explicar el proceso de comunicación (20\%)

- $\quad$ Originalidad de la propuesta $(20 \%)$

\footnotetext{
${ }^{3}$ Recordad que estamos ante una actividad académica. Utilizad un lenguaje correcto y sed respetuosos con vuestros compañeros.
} 